\title{
Ultrasonic versus jet nebulization of iloprost in severe pulmonary hypertension
}

\author{
T. Gessler*, T. Schmehl*, M.M. Hoeper", F. Rose*, H.A. Ghofrani*, H. Olschewski*, \\ F. Grimminger*, W. Seeger*
}

Ultrasonic versus jet nebulization of iloprost in severe pulmonary hypertension. T. Gessler, T. Schmehl, M.M. Hoeper, F. Rose, H.A. Ghofrani, H. Olschewski, F. Grimminger, W. Seeger. (C) ERS Journals Ltd 2001.

ABSTRACT: Inhalation of iloprost, a stable prostacyclin analogue, is a promising perspective in the treatment of pulmonary hypertension. In initial clinical studies, a conventional jet nebulizer system was successfully used to decrease pulmonary vascular resistance and pressure, requiring however, up to twelve inhalations of 12-15 min per day. The aim of this study was to investigate if the application of an equal dose of iloprost at a drastically reduced duration of inhalation with the use of a more efficient ultrasonic nebulizer, leads to comparable haemodynamic effects, without escalation of side effects.

The physical features of the jet nebulizer system (Ilo-Neb ${ }^{\mathrm{TM}}$ ) and the ultrasonic nebulizer (Multisonic Compact ${ }^{\mathrm{TM}}$ ) were characterized by laser diffractometry and a $\mathrm{Tc}^{99 \mathrm{~m}}$-tracer technique. Mass median aerodynamic diameters were $3.2 \mu \mathrm{m}$ for the jet and $3.9 \mu \mathrm{m}$ for the ultrasonic nebulizer. Total output (mean \pm SD) was $60 \pm 7 \mu \mathrm{L} \cdot \mathrm{min}^{-1}$ (jet) and $163 \pm 15 \mu \mathrm{L} \cdot \mathrm{min}^{-1}$ (ultrasonic), and efficiency of the devices was $39 \pm 3 \%$ (jet) and $86 \pm 5 \%$ (ultrasonic). Based on these data, a total inhalative dose of $2.8 \mu \mathrm{g}$ iloprost was delivered by jet nebulization within $12 \mathrm{~min}$ and by ultrasonic nebulization within $4 \mathrm{~min}$, in 18 patients with severe primary and secondary pulmonary hypertension (New York Heart Association class III and IV), in a randomized crossover design. Haemodynamics were assessed by right heart catheterization.

Inhalation with the ultrasonic device and jet nebulizer, reduced mean \pm SEM pulmonary artery pressure from $54.3 \pm 2.1$ to $47.1 \pm 2.0$ and from $53.5 \pm 2.2$ to $47.0 \pm 2.2 \mathrm{mmHg}$, respectively, and mean \pm SEM pulmonary vascular resistance from $1073 \pm 109$ to $804 \pm 87$ and from $1069 \pm 125$ to $810 \pm 83 \mathrm{dyn} \cdot \mathrm{s}^{\cdot} \mathrm{cm}^{-5}$, respectively. Both modes of aerosolization were well tolerated.

In conclusion, due to the markedly higher efficiency and output of the ultrasonic device, wastage of drug is largely avoided and the duration of inhalation can be shortened to one-third, with comparable haemodynamic effects and without enforcing side effects.

Eur Respir J 2001; 17: 14-19.
*Dept of Internal Medicine, JustusLiebig-University of Giessen, Giessen, Germany, ${ }^{\#}$ Dept of Respiratory Medicine, Hannover Medical School, Hannover, Germany.

Correspondence: W. Seeger Dept of Internal Medicine II Justus-Liebig-University

Klinikstr. 36

Giessen

D-35392

Germany

Fax: 496419942359

Keywords: Iloprost nebulization

pulmonary hypertension

Received: July 242000

Accepted after revision October 42000
Severe pulmonary hypertension is a life threatening disease, characterized by an increase in arterial pressure and vascular resistance in the pulmonary circulation [1]. Dyspnoea and reduced exercise capacity are the prominent clinical symptoms; death is most closely associated with an increase in right atrial pressure and a decrease in cardiac output due to right-sided heart failure [2]. Several investigations with intravenous administration of prostacyclin have demonstrated the vasodilatory capacity of this prostanoid in primary pulmonary hypertension (PPH) [3-5] as well as in forms of secondary pulmonary hypertension $(\mathrm{SPH})[6$, 7]. Moreover, in a controlled study continuous prostacyclin infusion was shown to improve exercise capacity and survival in patients suffering from severe PPH [8]. Disadvantages of this intravenous approach are the lack of pulmonary selectivity, giving way to systemic side effects, as well as infectious complications related to the long-term use of an intravenous catheter.

In a recent approach to overcome these shortcomings, aerosolization of the stable prostacyclin analogue iloprost was employed for pulmonary vasodilation in both PPH and severe SPH [9-13]. Preferential vasorelaxation in the pulmonary circulation was demonstrated with this approach, the maximum pulmonary vasodilatory potency corresponding to that of intravenous prostacyclin. At present, limited data on long-term clinical use of iloprost inhalation are available, indicating an improvement in exercise capacity and pulmonary haemodynamics after 12 months of iloprost aerosol therapy in 24 patients with PPH [14]. Phase II (randomized, parallel-group comparative clinical) as well as phase III (double-blind, randomized, placebo-controlled clinical) studies addressing the impact of iloprost nebulization on exercise capacity and mortality in PPH and severe secondary pulmonary hypertension are currently under way.

In all previous studies investigating short-term or long-term iloprost nebulization [9-14], a continuous output jet nebulizer with a reservoir and filter system was used. However, the limited output of this device requires long inhalation periods of $12-15 \mathrm{~min}$ for 
delivery of an adequate iloprost dose for pulmonary vasodilation. Moreover, the therapeutic use of iloprost aerosolization in pulmonary hypertension demands multiple daily inhalation manoeuvres, since the pulmonary vasodilatory effect of each single inhalation levels off within $\sim 1 \mathrm{~h}$, thus resulting in a total duration of inhalation of up to $3 \mathrm{~h}$ per day. In addition, limited efficiency of the jet nebulizer system causes a notable waste of the drug. Therefore, a reduction of inhalation time with the use of a more efficient nebulizer system will markedly improve iloprost aerosol therapy. A recently developed ultrasonic nebulizer device might offer the possibility to overcome these limitations. However, no data on aerosol delivery of prostanoids with this different technical approach are presently available. The present study characterized the physical features of the ultrasonic nebulizer. Based on these data, a comparison of the haemodynamic effects of an equivalent dose of iloprost delivered in a crossover design by the jet nebulizer within $12 \mathrm{~min}$ and the ultrasonic device within $4 \mathrm{~min}$ during right heart catheter tests, was performed. Patients with severe primary and secondary pulmonary hypertension were used. It was investigated whether the iloprost application at a notably shorter duration of inhalation would result in comparable pulmonary vasodilatory effects without enforcing side effects.

\section{Methods}

\section{Physical characterization of the devices}

The following parameters of the devices were analysed: particle size distribution, total output of the nebulizer, effective output at the mouthpiece and aerosol loss in the different components of the device. Mass median aerodynamic diameter (MMAD) and geometric standard deviation (GSD) of the aerosol were determined using a laser diffractometer (Helos ${ }^{\mathrm{TM}}$; Sympatec, Clausthal, Germany) at room temperature and with a distance of $1 \mathrm{~cm}$ between mouthpiece and laser beam. The jet nebulizer system investigated in this study (Ilo-Neb ${ }^{\text {TM}}$; Nebu-Tec company, Elsenfeld, Germany) consisted of a Bennett-Raindrop ${ }^{\text {TM }}$ jet nebulizer, a reservoir, filters, valves and tubes and was driven by a Pari Boy ${ }^{\text {TM }}$ compressor (Pari, Starnberg, Germany) at $80 \mathrm{kPa}$ (fig. 1). For the ultrasonic nebulizer system (Multisonic Compact ${ }^{\mathrm{TM}}$; Schill company, Probstzella, Germany) with an operating ultrasound frequency of 1.7 $\mathrm{MHz}$ (fig. 2), an airflow of $40 \mathrm{~L} \cdot \mathrm{min}^{-1}$ was applied for particle size measurements. The filled-in volume was $4 \mathrm{~mL}$ iloprost diluted in physiological saline for both devices.

The total output of the nebulizers and the output at the mouthpiece were quantified by a $\mathrm{Tc}^{99 \mathrm{~m}}$-tracertechnique with an additional filter at the mouthpiece of the system for aerosol trapping. To mimic aerosol inhalation in patients, a volunteer performed the inhalation manoeuvres through the filter at the mouthpiece (tidal volume $\sim 1.5 \mathrm{~L}$, breathing frequency $\sim 11 \cdot \mathrm{min}^{-1}$, inspiration:expiration ratio $\sim 1: 1.8)$. After each inhalation period (12 min for the jet nebulizer, $4 \mathrm{~min}$ for the ultrasonic nebulizer), the systems were disassembled a)

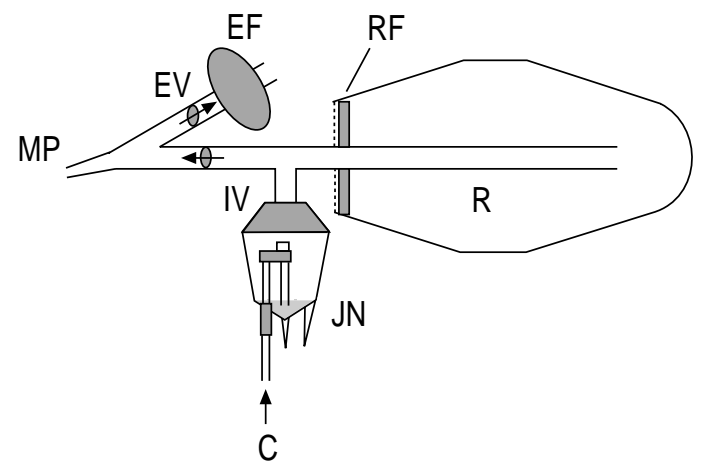

b)

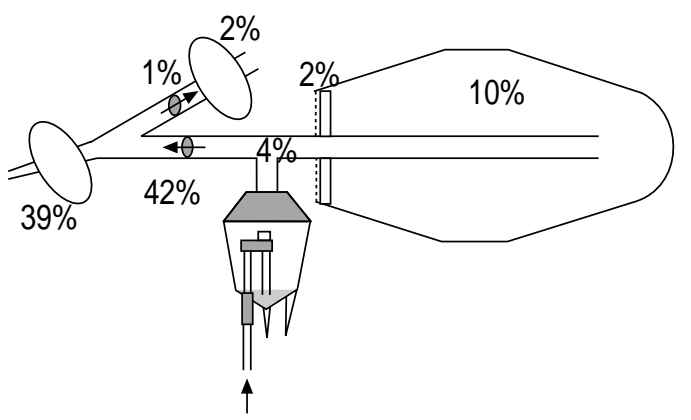

Fig. 1. - Schematic depiction of a) the jet nebulizer device, with b) deposition fractions of a $\mathrm{Tc}^{99 \mathrm{~m}}$-labelled test aerosol in the different parts of the device being given as per cent of total output. In these experiments, the output at mouthpiece was captured in an additional filter mounted at this site. EF: expiration filter; EV: expiration valve; MP: mouthpiece; IV: inspiration valve; RF: reservoir filter; R: reservoir; JN: Bennett-Raindrop ${ }^{\mathrm{TM}}$ jet nebulizer; C: Pariboy ${ }^{\mathrm{TM}}$ Compressor.

and the activity deposited in the various parts of the nebulizer was determined using a gamma-counter. The efficiency, defined as the ratio of the output at the mouthpiece to total output of the nebulizer, was calculated from the activities in the components.

\section{Patients}

A total of 18 patients with severe pulmonary hypertension was included in the investigation, all of whom were classified as New York Heart Association class III or IV. Seven patients suffered from primary pulmonary hypertension and 11 patients showed pulmonary hypertension related to thromboembolism (six patients), connective tissue disease (three patients), lung fibrosis (one patient) and portal hypertension (one patient) (diagnosis according to World Health Organization conference [1]). Diagnostic procedures included transthoracic or transoesophageal echocardiography, chest radiography, high resolution and spiral computer tomography of the lung, ventilation-perfusion scans, lung function testing including carbon monoxide-diffusion capacity, pulmonary angiograms and pulmonary artery catheter. Baseline values for mean \pm SEM pulmonary artery pressure at rest, and pulmonary vascular resistance were $54.1 \pm 2.2 \mathrm{mmHg}$ and $1076 \pm 121 \mathrm{dyn} \cdot \mathrm{s}^{\cdot} \mathrm{cm}^{-5}$, respectively.

All patients gave written informed consent to the test trial, which was approved by the local institutional ethics committees of the participating centres. 
a)

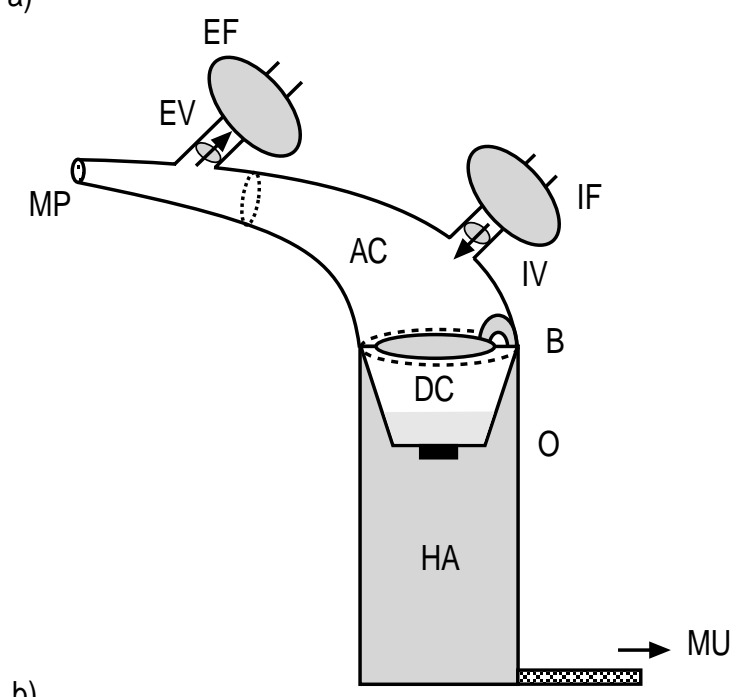

b)

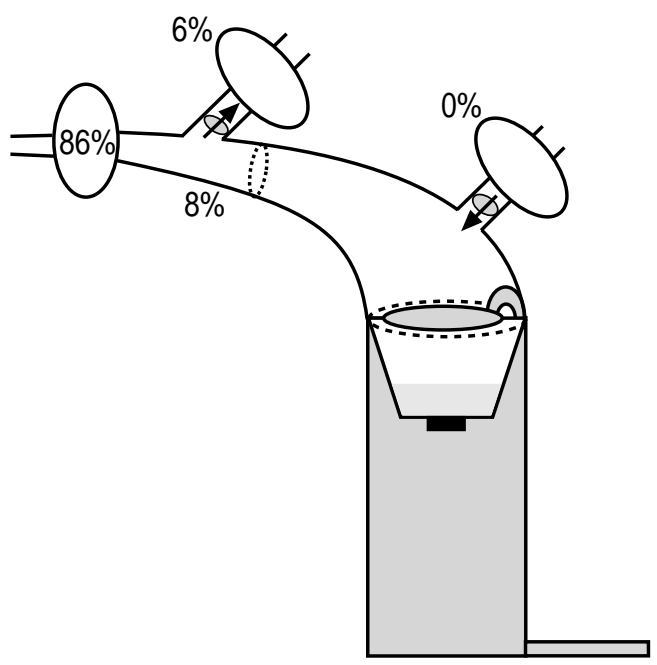

Fig. 2. - Schematic depiction of a) the ultrasonic nebulizer device, with b) deposition fractions of a $\mathrm{Tc}^{99 \mathrm{~m}}$-labelled test aerosol in the different parts of the device being given as per cent of total output. In these experiments, the output at mouthpiece was captured in an additional filter mounted at this site. EF: expiration filter; EV: expiration valve; MP: mouthpiece; AC: aerosol chamber; DC: drug chamber; HA: hand apparatus; IV: inspiration valve; IF: inspiration filter; B: baffle; O: oscillator; MU: main unit.

\section{Catheter and inhalation protocol}

Before starting the device comparison with inhaled iloprost, a fibreoptic thermodilution pulmonary artery catheter was employed for measurement of pulmonary artery pressure (PAP), pulmonary artery wedge pressure (PAWP), central venous pressure (CVP) and cardiac output $(\mathrm{CO})$. A femoral artery catheter was used to assess systemic arterial pressure (SAP). Based on these data, cardiac index $(\mathrm{CI})$, pulmonary vascular resistance (PVR) and systemic vascular resistance (SVR) were calculated.

Each patient inhaled with both devices in a randomized order. The first inhalation was performed after achieving a stable baseline of haemodynamic variables; the second inhalation started $2 \mathrm{~h}$ after the end of the first inhalation. PAP, PAWP, CVP, CO and SAP were recorded before (baseline) and $0,5,15,30$ and $60 \mathrm{~min}$ after the end of each inhalation.

For inhalation manoeuvres with the jet nebulizer, iloprost was diluted in saline to a final concentration of $10 \mu \mathrm{g} \cdot \mathrm{mL}^{-1}$, and $4 \mathrm{~mL}$ of the solution were placed in the nebulizer. The nebulizer was then driven with room air at a pressure of $80 \mathrm{kPa}$ for an inhalation period of $12 \mathrm{~min}$. For inhalation manoeuvres with the ultrasonic nebulizer system, iloprost was diluted in saline to a final concentration of $5 \mu \mathrm{g} \cdot \mathrm{mL}^{-1}$ and $4 \mathrm{~mL}$ of the solution were introduced into the nebulizer. Patients then inhaled the nebulized drug for a period of $4 \mathrm{~min}$. This procedure was based on the physical characterizations of the nebulizers, targeting to achieve an equivalent dose $(2.8 \mu \mathrm{g})$ of the vasodilatory prostanoid at the mouthpiece with both systems.

\section{Statistics}

All values are presented as means \pm SEM unless otherwise noted. Statistical comparisons of haemodynamic parameters at $0,5,15,30 \mathrm{~min}$ after inhalation versus baseline (pre inhalation) were performed for each device using paired t-tests. The exact Wilcoxon matched pair signed-rank test was used if data did not show normal distribution in Kolmogorov-Smirnov tests. For multiple testing, the Holm correction was applied [15].

To compare the influence of the different devices on haemodynamic parameters, the differences of post versus pre inhalation values for both devices were calculated. These differences were analysed with the same statistical procedures as described above.

\section{Results}

The physical parameters of both nebulizers are shown in table 1 . In figure 1 and 2, the aerosol deposition in the different parts of the devices is depicted: $61 \%$ of the generated aerosol was lost within the jet nebulizer device, compared to only $14 \%$ in the ultrasonic device. Based on these data, the "standard" iloprost aerosol application, as investigated in previous clinical studies with employment of the currently tested jet nebulizer device, was calculated to result in a total iloprost dose at the mouthpiece of $2.8 \mu \mathrm{g}(12 \mathrm{~min}$ inhalation period, iloprost concentration $\left.10 \mu \mathrm{g} \cdot \mathrm{mL}^{-1}\right)$. To achieve an equivalent dose when using the ultrasonic nebulizer device, the iloprost concentration was reduced to $5 \mu \mathrm{g} \cdot \mathrm{mL}^{-1}$ and the inhalation time to 4 min to match the higher output at the mouthpiece of the ultrasonic nebulizer.

The kinetics of haemodynamic parameters pre-, and up to one hour postiloprost inhalation, for both devices are shown in figures 3 and 4 . The iloprost inhalations with both devices were well tolerated. Side effects, such as cough or flush occurred in only few patients to very moderate degrees and never led to discontinuation of inhalation. The iloprost delivery via both devices resulted in a significant reduction of PAP, PVR and the PVR/SVR ratio, as well as in an increase of CI (figs 3 and 4; table 2). In addition, some minor and 
Table 1. - Comparison of physical parameters of the nebulizer devices

\begin{tabular}{|c|c|c|}
\hline & $\begin{array}{c}\text { Jet } \\
\text { nebulizer } \\
\text { system }\end{array}$ & $\begin{array}{l}\text { Ultrasonic } \\
\text { nebulizer } \\
\text { system }\end{array}$ \\
\hline MMAD $\mu \mathrm{m}$ & $3.2 \pm 0.1$ & $3.9 \pm 0.2$ \\
\hline GSD & $1.8 \pm 0.0$ & $1.6 \pm 0.1$ \\
\hline $\begin{array}{l}\text { Total output of nebulizer } \\
\mu \mathrm{L} \cdot \mathrm{min}^{-1}\end{array}$ & $60 \pm 7$ & $163 \pm 15$ \\
\hline $\begin{array}{l}\text { Output at mouthpiece } \\
\mu \mathrm{L} \cdot \mathrm{min}^{-1}\end{array}$ & $23 \pm 3$ & $140 \pm 13$ \\
\hline Efficiency $\%$ & $39 \pm 3$ & $86 \pm 5$ \\
\hline
\end{tabular}

Data are presented as mean $\pm \mathrm{SD} ; \mathrm{n}=6$. MMAD: mass median aerodynamic diameter; GsD: geometric standard deviation.

rapidly transient decrease in systemic arterial pressure was noted. All changes in haemodynamic variables largely levelled off within $\sim 1 \mathrm{~h}$. There was no statistically significant difference between responses to the jet and ultrasonic nebulization techniques, except for the CI, which increased more rapidly and more prominently when applying the iloprost dose in the ultrasonic nebulization manoeuvre, as compared to the standard jet nebulization protocol (increase in CI 0.44 $\mathrm{L} \cdot \mathrm{min}^{-1} \cdot \mathrm{m}^{-2}$ versus $0.19 \mathrm{~L} \cdot \mathrm{min}^{-1} \cdot \mathrm{m}^{-2}$ assessed $5 \mathrm{~min}$ after termination of inhalation manoeuvre; $\mathrm{p}<0.05$ ).

\section{Discussion}

The physical characterization of both the jet and ultrasonic nebulizers, demonstrated that particle sizes of both systems are within a range suitable for alveolar deposition [16-18]. Particle sizes of the presently investigated ultrasonic nebulizer (Multisonic Compact $^{\text {TM }}$ ) are dependent on the gas flow through the system; the applied flow of $40 \mathrm{~L} \cdot \mathrm{min}^{-1}$ matches realistic mean inspiratory flow conditions, resulting in a MMAD of $3.9 \mu \mathrm{m}$.

The total output of the ultrasonic nebulizer $\left(163 \mu \mathrm{L} \cdot \mathrm{min}^{-1}\right)$ is 2.7 times higher than that of the jet nebulizer. The difference between the two systems is even more pronounced with regard to the output at mouthpiece: this parameter, describing the amount of aerosol delivered de facto to the inhaling patient, is more than six times higher in the ultrasonic nebulizer system as compared to the jet nebulizer. This is mainly due to a notable aerosol loss at the inspiration valve of the jet nebulizer device (fig. 1), with preferential deposition of large particles. The design of the ultrasonic nebulizer does not require any valve in the inspiratory aerosol flow, leading to a high efficiency of the device: $86 \%$ of the total aerosol output is available at the mouthpiece for inhalation. Moreover, the ultrasonic device offers, due to its compact construction, the advantage of an easy handling and maintenance, as compared to the jet nebulizer.

Both systems avoid drug contamination of the environment by the use of filters, thereby minimizing the risk of drug exposure to the medical staff. This is of particular importance when aerosolizing highly efficacious drugs, such as vasoactive agents or antibiotics, as demonstrated for pentamidine in recent studies [19, 20].

Based on the data of the physical characterization, the inhalation time for delivery of an equivalent iloprost dose at the mouthpiece $(2.8 \mu \mathrm{g})$ was reduced from $12 \mathrm{~min}$ with the jet nebulizer system to $2 \mathrm{~min}$ with the ultrasonic nebulizer, when retaining the same concentration of the iloprost solution $\left(10 \mu \mathrm{g} \cdot \mathrm{mL}^{-1}\right)$. In preliminary catheter investigations, however, some increase in systemic side effects was observed when administering the total iloprost dose of $2.8 \mu \mathrm{g}$ via the inhalation route for such a short time period. Therefore, we reduced the iloprost concentration from $10 \mu \mathrm{g} \cdot \mathrm{mL}^{-1}$ to 5 $\mu \mathrm{g} \cdot \mathrm{mL}^{-1}$ when employing the ultrasonic nebulizer, and consequently doubled the inhalation time to $4 \mathrm{~min}$ with this device. This inhalation protocol was generally well tolerated. Furthermore, by diluting the prostanoid solution, drug waste in the dead space of the nebulizer was reduced.

When directly comparing the haemodynamic effects of equivalent iloprost doses delivered either by jet or ultrasonic nebulization in a crossover design, a marked pulmonary vasodilation with a decrease in pulmonary artery pressure and pulmonary vascular resistance, and increase in CI was noted in response to both modes of aerosol administration. Strength and time course of the iloprost effect were comparable for both devices. Thus, the total amount of inhaled iloprost and not the duration of the inhalation manoeuvre (4 versus 12 min) is obviously the main determinant for both the strength and the duration of the pulmonary vasodilation effect. This is also true for the systemic effects, as both modes of aerosol administration caused preferential pulmonary vasodilation (reflected by a decrease

Table 2. - Haemodynamic parameters pre- and postinhalation (greatest effects)

\begin{tabular}{lcccc}
\hline & \multicolumn{2}{c}{ Jet nebulizer system } & & \multicolumn{2}{c}{ Ultrasonic nebulizer system } \\
\cline { 2 - 3 } & Pre & Post & Pre & Post \\
\hline $\mathrm{mPAP} \mathrm{mmHg}$ & $53.5 \pm 2.2$ & $47.0 \pm 2.2$ & $54.3 \pm 2.1$ & $47.1 \pm 2.0$ \\
PVR dyn $\cdot \mathrm{cm}^{-5}$ & $1069 \pm 125$ & $810 \pm 83$ & $1073 \pm 109$ & $804 \pm 87$ \\
$\mathrm{CI} \mathrm{L} \cdot \mathrm{min}^{-1} \cdot \mathrm{m}^{-2}$ & $2.24 \pm 0.17$ & $2.48 \pm 0.15^{*}$ & $2.22 \pm 0.17$ & $2.66 \pm 0.19 *$ \\
PVR/SVR & $0.56 \pm 0.04$ & $0.49 \pm 0.04$ & $0.56 \pm 0.03$ & $0.50 \pm 0.03$ \\
$\mathrm{mSAP} \mathrm{mmHg}$ & $91.8 \pm 3.8$ & $86.3 \pm 2.7$ & $90.6 \pm 2.5$ & $82.5 \pm 2.4$ \\
SVR dyn $\cdot \mathrm{s} \cdot \mathrm{cm}^{-5}$ & $1877 \pm 135$ & $1612 \pm 100$ & $1874 \pm 124$ & $1462 \pm 113$ \\
\hline
\end{tabular}

mPAP: mean pulmonary artery pressure; PVR: pulmonary vascular resistance; CI: cardiac index; SVR: systemic vascular resistance; PVR/SVR: ratio of PVR tp SVR; mSAP: mean systemic artery pressure; Pre: pre-inhalation value; Post: extreme value up to $60 \mathrm{~min}$ postinhalation (all extreme values are minimums except those marked with * which are maximum). Values are given as mean \pm SEM for $n=18$ patients. 

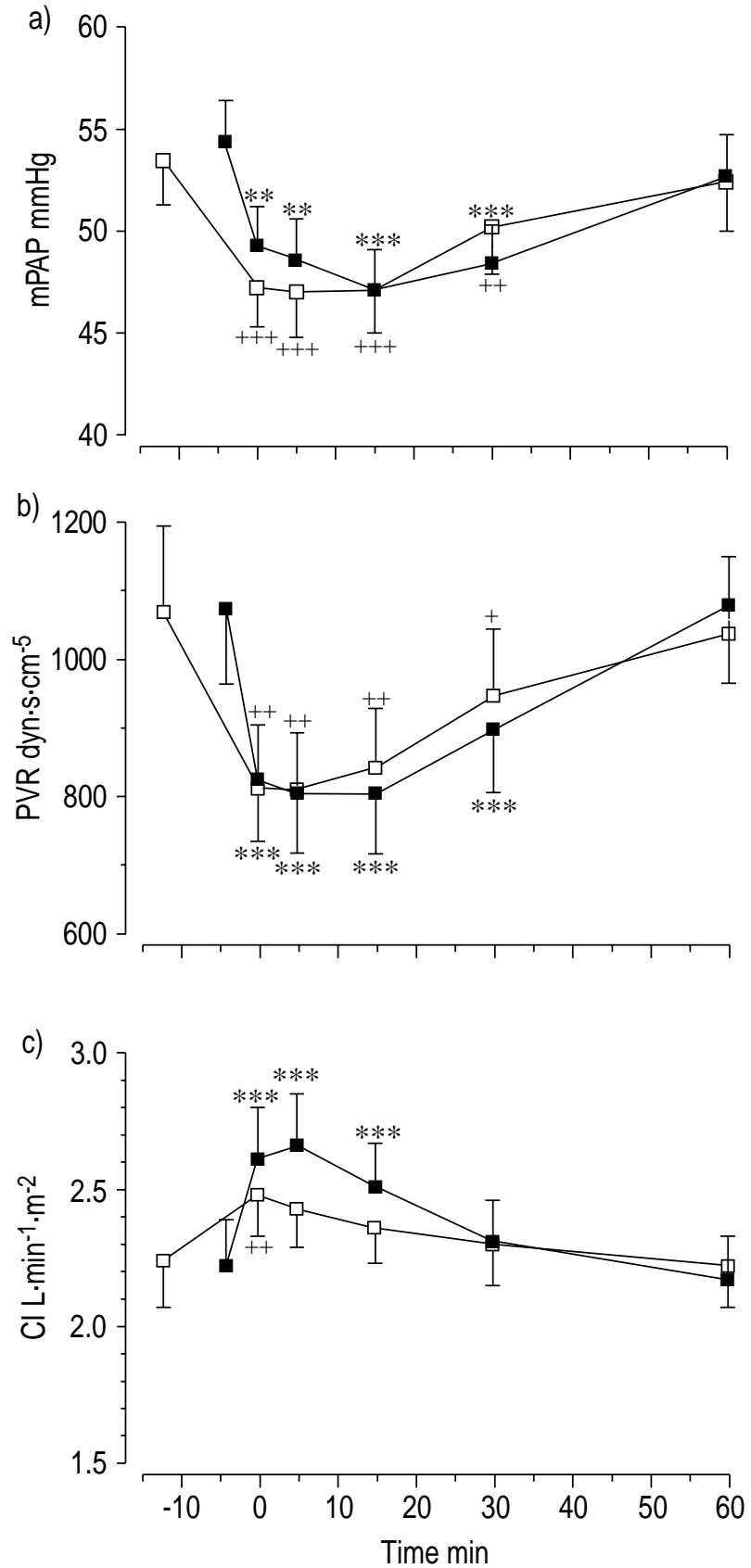

Fig. 3. - Responses of mean pulmonary artery pressure (mPAP), pulmonary vascular resistance (PVR) and cardiac index (CI) to iloprost inhalation $(2.8 \mu \mathrm{g})$ via jet nebulizer $(12 \mathrm{~min}$; $\square)$ and ultrasonic nebulizer (4 min; $\mathbf{\square})$. To normalize for the different length of the inhalation period, time was set at zero at the end of the aerosolization manoeuvre for both techniques. Statistical differences between pre- and postaerosolization data are indicated for both approaches $(*: \mathrm{p}<0.05 ; * *: \mathrm{p}<0.01 ; * * *$ : $\mathrm{p}<0.001$ for ultrasonic nebulization; ${ }^{+}: \mathrm{p}<0.05$; $^{++}: \mathrm{p}<0.01$; $^{+++}: \mathrm{p}<0.001$ for jet nebulization).

in the PVR/SVR ratio), with a very minor drop in systemic arterial pressure. Although not significantly different by statistical analysis (excepting CI increase), there was a tendency for a more prominent pulmonary and systemic vasodilatation potency (with corresponding cardiac output response) in the early postaerosolization period upon employment of the ultrasonic
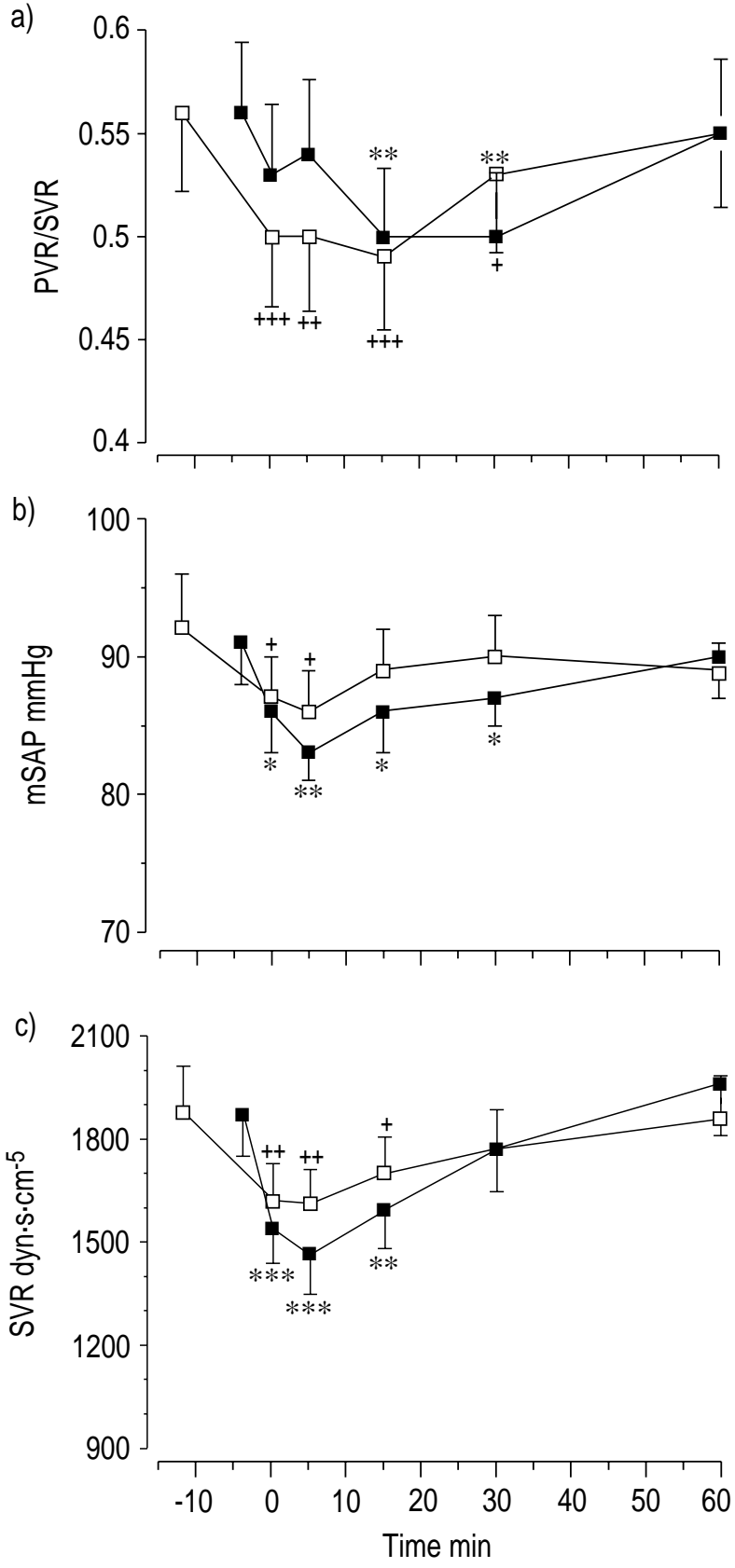

Fig. 4. - Responses of the ratio of pulmonary vascular resistance to systemic vascular resistance (PVR/SVR), mean systemic artery pressure (mSAP) and systemic vascular resistance (SVR) to iloprost inhalation $(2.8 \mu \mathrm{g})$ via jet nebulizer $(12 \mathrm{~min} ; \square)$ and ultrasonic nebulizer ( $4 \mathrm{~min} \mathbf{a})$. To normalize for the different length of the inhalation period, time was set at zero at the end of the aerosolization manoeuvre for both techniques. Statistical differences between pre- and postaerosolization data are indicated for both approaches $(*: \mathrm{p}<0.05 ; * *: \mathrm{p}<0.01 ; * * *: \mathrm{p}<0.001$ for ultrasonic nebulization; ${ }^{+}: \mathrm{p}<0.05 ;^{++}: \mathrm{p}<0.01 ;^{+++}: \mathrm{p}<0.001$ for jet nebulization).

nebulization manoeuvre. These observations might support the hypothesis of a spill-over to the systemic circulation and hence systemic vasodilatation acting as a driving force of increased cardiac output.

The pulmonary vasodilator effect levelled off within $\sim 1 \mathrm{~h}$, independent of the device used. Therefore, the inhalation frequency remains unchanged with up to 12 
inhalations per day; the notably shorter duration of inhalation with the new device, however, may improve compliance and quality of life of the patients. Nevertheless, the long-term impact of iloprost aerosol therapy in pulmonary hypertension patients has still to be confirmed by the ongoing double-blind randomized studies.

The maximum decrease in pulmonary artery pressure and resistance in response to $2.8 \mu \mathrm{g}$ iloprost delivered by jet or ultrasonic nebulization in the present study ranged somewhat lower than the maximum pulmonary vasodilator effect previously described for this approach in severe pulmonary hypertension [9-13]. However, these previous studies included mostly patients suffering from $\mathrm{PPH}$ or pulmonary hypertension associated to connective tissue disease. In contrast, the present investigation included more SPH than PPH patients, including six patients with severe pulmonary hypertension related to thromboembolism (classed as SPH patients). This fact may well explain the somewhat lower pulmonary vasodilator response in the present study as compared to the previous investigations with iloprost aerosol delivery.

In conclusion, ultrasonic nebulization is suitable for inhalation of iloprost in severe pulmonary hypertension, inducing preferential pulmonary vasodilation. Markedly higher efficiency and output of the currently investigated ultrasonic device, in comparison to a standard jet aerosolization technique, avoids wastage of drug and allows shortening of the inhalation time to $\sim 30 \%$, with comparable haemodynamic effects. The delivery of a standard iloprost dose of $2.8 \mu \mathrm{g}$ in the notably reduced inhalation time did not induce side effects and was well tolerated by all patients. Long-term use of the ultrasonic nebulization device, performed in selected patients beyond the scope of the present study, as yet has shown no technical drawbacks. Thus employment of ultrasonic aerosol generation offers more effective alveolar deposition of vasoactive drugs in severe pulmonary hypertension, as compared to conventional jet nebulization.

Acknowledgements. The authors thank M. Hollenhorst for statistical assistance and R.L. Snipes for carefully reviewing the manuscript. Parts of T. Gessler's thesis are incorporated into this report.

\section{References}

1. Executive summary from the World Symposium on Primary Pulmonary Hypertension 1998. Rich S, Ed. Available from the World Health Organization at http://www.who.int/ncd/cvd/pph.html.

2. D'Alonzo GE, Barst RJ, Ayres SM, et al. Survival in patients with primary pulmonary hypertension. Results from a national prospective registry. Ann Intern Med 1991; 115: 343-349.

3. Higenbottam T, Wheeldon D, Wells F, Wallwork J. Long-term treatment of primary pulmonary hypertension with continuous intravenous epoprostenol (prostacyclin). Lancet 1984; 1: 1046-1047.

4. Higenbottam $T$. The place of prostacyclin in the clinical management of primary pulmonary hypertension. Am Rev Respir Dis 1987; 136: 782-785.

5. Rubin LJ, Mendoza J, Hood M, et al. Treatment of primary pulmonary hypertension with continuous intravenous prostacyclin (epoprostenol). Results of a randomized trial. Ann Intern Med 1990; 112: 485-491.

6. Humbert M, Sanchez O, Fartoukh M, et al. Shortterm and long-term epoprostenol (prostacyclin) therapy in pulmonary hypertension secondary to connective tissue diseases: results of a pilot study. Eur Respir J 1999; 13: 1351-1356.

7. McLaughlin VV, Genthner DE, Panella MM, Hess DM, Rich S. Compassionate use of continuous prostacyclin in the management of secondary pulmonary hypertension: a case series. Ann Intern Med 1999; 130: 740-743.

8. Barst RJ, Rubin LJ, Long WA, et al. A comparison of continuous intravenous epoprostenol (prostacyclin) with conventional therapy for primary pulmonary hypertension. N Engl J Med 1996; 334: 296-301.

9. Olschewski H, Walmrath D, Schermuly R, Ghofrani HA, Grimminger F, Seeger W. Aerosolized prostacyclin and iloprost in severe pulmonary hypertension. Ann Intern Med 1996; 124: 820-824.

10. Olschewski H, Ghofrani HA, Walmrath D, Temmesfeld-Wollbrück B, Grimminger F, Seeger W. Recovery from circulatory shock in severe primary pulmonary hypertension (PPH) with aerosolization of iloprost. Intensive Care Med 1998; 24: 631-634.

11. Olschewski H, Ghofrani HA, Walmrath $\mathrm{D}$, et al. Inhaled prostacyclin and iloprost in severe pulmonary hypertension secondary to lung fibrosis. Am J Respir Crit Care Med 1999; 160: 600-607.

12. Olschewski H, Ghofrani HA, Schmehl T, et al. Inhaled iloprost to treat severe pulmonary hypertension: an uncontrolled trial. Ann Intern Med 2000; 132: 435-443.

13. Hoeper MM, Olschewski H, Ghofrani HA, et al. A comparison of the acute haemodynamic effects of inhaled nitric oxide and aerosolized iloprost in primary pulmonary hypertension. J Am Coll Cardiol 2000; 35: 176-182.

14. Hoeper MM, Schwarze M, Ehlerding S, et al. Longterm treatment of primary pulmonary hypertension with aerosolized iloprost, a prostacyclin analogue. $N$ Engl J Med 2000; 342: 1866-1870.

15. Holm S. A simple sequentially rejective multiple test procedure. Scand J Statistics 1979; 6: 65-70.

16. Morrow PE. Factors determining hygroscopic aerosol deposition in airways. Physiol Rev 1986; 66: 330-376.

17. Stahlhofen W, Gebhart J, Heyder J. Experimental determination of the regional deposition of aerosol particles in the human respiratory tract. Am Ind Hyg Assoc J 1980; 41: 385-398a.

18. Heyder J, Gebhart J, Stahlhofen W. Inhalation of aerosols: particle deposition and retention. In: Willeke $\mathrm{K}$, ed. Generation of Aerosols and Facilities for Exposure Experiments. Ann Arbor, Ann Arbor Science, 1980; pp. 65-104.

19. O'Riordan TG, Smaldone GC. Exposure of health care workers to aerosolized pentamidine. Chest 1992; 101: 1494-1499.

20. Balmes JR, Estacio PL, Quinlan P, Kelly T, Corkery K, Blanc P. Respiratory effects of occupational exposure to aerosolized pentamidine. J Occup Environ Med 1995; 37: 145-150. 